\title{
Antagonist Innovation: technologies, practices and innovation in the War on Drugs
}

\section{Introduction}

Antagonistic relations can create conditions for innovation. In the so-called War on Drugs (WoD), law enforcement, military, and drug smugglers have engaged in the production, modification, and maintenance of technological artifacts. State agencies aim to stop the production and movement of illicit products and drug smugglers to produce, camouflage and transport their cargo. The findings presented in this article are the result of documentary material and ethnographic work with the Colombian Navy and Colombian drug smugglers. I focus my attention in the recent history of the binary interdiction/evasion: the symbiotic set of practices and technologies deployed by drug smugglers to transport drugs and by law enforcement and military to thwart those efforts. I argue that the process of technological innovation in the $\mathrm{WoD}$ can be explained as the result of the interaction between two set of uncoordinated, yet connected, set of actions, that I call antagonist innovation, which is carried out by users on both sides attempting to outmaneuver their rivals, in a context of incomplete knowledge of the actions undertaken by their rival.

To present the extent of this antagonist innovation, I discuss two different kinds of technologies used in the maritime interdiction environment, one used by drug smugglers to transport drugs and one used by the Colombian Coast Guard to stop smugglers' boats. The narcosubs and the patrol boat. These artifacts represent some of the key actions in which 
Preprint currently under consideration by ST\&HV: Please do not cite without the author's consent

competing complex sociotechnical systems, drug smugglers and military display their tools/knowledge, creating the conditions that further help the two sides of the binary to coevolve. The evidence and arguments presented here, I believe help to convey a richer representation of the technological change in the WoD challenging the highly stereotyped versions of both smugglers and enforcement agencies in relation with technology.

\section{The War on Drugs}

The term War on Drugs has been used to describe the efforts of the U.S. government to enforce anti-drug policies, i.e., an enforcement-focused approach, in which controlling the supply of illicit drugs is the main goal with an increasing participation of the military in the interdiction of illicit flows of drugs and in the arrest of drug traffickers. The early declaration of the 'War on Drugs' was during the Richard Nixon presidency and entailed the reorganization of drug policy around repression of consumption by creating The National Institute on Drug Abuse (NIDA) and the Drug Enforcement Administration (DEA) (Boville 2004). However, the modern era of the WoD began with the presidency of Ronald Reagan in the early 1980s. The Reagan government considered the production and traffic of illicit drugs as a threat to U.S. national security and allowed civil authorities, to use military technology, intelligence resources, and at the time sophisticated network of Navy E-2C (the so-called mini AWACKs) which are radar planes operating out of Jacksonville, Florida, in the WoD, while the U.S Navy participated in the interdiction of drug smugglers in international waters (Chepesiuk 1999) and U.S armed forces were also deployed in the Andean countries with the aim of stopping the production of illicit drugs in the source countries (Bagley 1991). 
The enforcement-focused approach was continued during the subsequent presidencies of George H. W. Bush and Bill Clinton. The Bush administration asked the military to play a major role in interdiction of illicit drugs, and increased military help to source countries and prioritized training both military and police forces. Enforcement of supply strategies were continued during the presidency of Bill Clinton (1993-2000). It was during the second term of Clinton that the infamous Plan Colombia was designed. Relationships between the U.S. government and the Colombian government during the presidency of Ernesto Samper (19941998) were hampered by the decision of the U.S. not to provide financial aid to Colombia because President Samper faced impeachment charges for receiving money from the 'Cali cartel' to fund his presidency campaign. During Samper's government the circumstantial alliance between the left wing guerrillas and the drug market deepened (Boville 2004). During the Samper Government the FARC-EP, one of the main guerrilla groups, was able to mobilize the cocaleros (coca farmers) against the central government in an effort to stop the fumigation of coca crops. Samper's successor Andres Pastrana (1998-2002) aligned to the strategy outlined out by the U.S. government. The strategy was clearly expressed in the Plan Colombia, launched in July 2000. The central goal of the Plan Colombia was to reduce the cultivation, processing, and distribution of illegal narcotics by 50 percent over a period of six years, starting in 2000. According to the United States Government Accountability Office (GAO), the United States funding for the military component of Plan Colombia was on average 540 million USD per year between 2000 and 2008. The Colombian government invested in the Plan Colombia approximately 812 million USD per year during the same period (Mejia 2016). The Plan Colombia contemplated an initial investment of 1.2 billon USD in counterdrug operations, but resulted in a package of 7.5 billion USD in aid, of which at least 75 percent was destined for the military and police forces (Rochlin 2011). During the 
same period, maritime routes were considered the main strategy for the transportation of cocaine from producers to transshipment and consumer countries.

Colombian smugglers use both the Caribbean Sea and the Pacific Ocean, the same spaces where legitimate commerce have traditionally been moved. These spaces are then the scenario of 'dispersed and heterogeneous flows of different categories of peoples and objects' (J Urry 2007). Most illicit drugs are moved in prosaic vessels. Locals have used most of those vessels for decades in their everyday activities, fishing, transporting of people or goods. Slight modifications allow for the transport of illicit drugs. The bulk of interdiction efforts are carried out by the patrol boat, until recently comprises old and new assorted vessels, which are constantly adapted and changed.

\section{Of Outlaw Users, cartels and networks}

Science and Technology Studies (STS), Innovation Studies (IS), and Innovation Management (IM) have highlighted the importance of users in the process of technological innovation. These fields have stressed particular aspects of user involvement with technology and demonstrated as Oudshoorn and Pinch state, users' capacities to shape technological innovation while developing different conceptual vocabularies (Russell and Williams 2002). To Flowers and Hendwood (2010), the complexities of user innovation call for complementarity between different perspectives. What Gambardella, Raasch and von Hippel (2016) named user innovation paradigms comprises several ways to understand who users are? The kind of innovation they produce? And the way they produce it. 
Users have played a central role in the shaping of activities and goods in fringe activities, such as pornography (Coopersmith 2000, 1998, 2006; Voss 2007), and the development of goods for the practice of extreme sports have called the attention of scholars from IS and STS (Hyysalo 2009; Shah 2006) Studies of the unruly users in the digital era, the hacker (Maxigas 2017; Söderberg 2017; Flowers 2008; Taylor 1999), and online piracy has led to the coining of the term outlaw user and outlaw innovation (Schulz and Wagner 2008). Recently Hyssalo, Ussenyuk y Whalen have introduced a geographical element in the study of user-driven innovation, researching transportation in the Russian North (Usenyuk, Svetlana; Whalen, Jack; Hyysalo 2016) exploring how non-coordinated actors without the presence of arenas of interaction can produce complex pieces of technology, dominating all aspects of the machines, despite attempts by manufacturers to take over. Technological innovation in the WoD, share some characteristics of the dispersed peer innovation as discussed by Hyssalo and Usenyuk (2015).

There have been few attempts to understand the use of technologies in the WoD. Drugs scholars, even when dealing with matters such as the movement of illicit drugs, (e.g. Gootenberg 2008) do not deal with technology. When dealing with, interpretations of the production of technologies in the $\mathrm{WoD}$, focus mostly on the smugglers' side. Presenting heroic accounts of smugglers ingenuity as the explanation of the dynamics of technological innovation in the WoD. Such versions have created an epic fictionalized accounts of drug trafficking and follow a traditional linear fashion of constant improvement. Such as the Pablo Escobar brother (Escobar and Fisher 2009), the infamous drug 'baron,' attempt to place the invention of narcobsubmerines as result of Pablo's inventiveness after watching a James Bond movie. 
Academic interpretations of the actions of drug traffickers stress either the centralized coordination of actions or flexible and networked strategies. In the former, the drug market is dominated by the competition between powerful cartels, who exert control through the indiscriminate use of violence and or bottomless resources to buy cutting-edge technologies outperforming competitors and enforcement agencies. The latter present flexibility and speed as strategies with which these organizations are said to change to out-fox slow and bureaucratic enforcement agencies and state.

The work of Zaitch (2002) and Kenney (2007a, 2007b, 2007c) among others was instrumental in demonstrating that smugglers are not organized in centralized and hierarchical organizations, in which a powerful boss, a "drug baron", and his/her associates can control and overview all the stages of production and distribution, flagging the role of kinship and local knowledge in drug smuggling practices. But they do not discuss said role, the innovations or the technological artifacts employed to smuggle, or the ones use by the military or Law Enforcement Agencies to thwart drug traffickers' actions. Townsend and Decker (2008), described actions and strategies and (up to some extent) discussed the artifacts, and provided invaluable empirical material, but they did so without any theory regarding technology or innovation.

\section{Methodology}

Researching technological innovation in the WoD presents several challenges. The access to data of actors that actively attempt to avoid being reported or quantified (Andreas 2003) is restricted. Coastal areas where illicit drugs are stored and shipped from, due to the lack of infrastructure, encourage locals to rely on local knowledge and stimulated creative solutions 
as a way to overcome challenges created by their distance from urban centers. Drug smuggling activities using custom-made artefacts, such as go-fast boats and narcosubmarines are concentrated in three areas of Colombia. Two of those are located in the Caribbean coast and one them in the Pacific coast, specifically the northern sector of La Guajira, (Map 1), in the Urabá and Darien areas of the Atlantic Coast, (Map 2), and on South Pacific Coast, specifically in the Department of Nariño (Map 3). These three border coastal regions are characterized by their relative distance from the central government with a weak or nonexistence presence of the state, and are highly unpoliced, where for extended periods have seen the constant competition and coexistence of armed non-state actors, access to such areas entail a high level of danger.

I have drawn on the broader STS theory as a guide to the methodological approach to formulate and to provide answers to the research questions. I have explicitly adopted the Biographies of Artefacts and Practices (BoAP) (Hyysalo, Pollock, and Williams 2018) approach to analyze the set of users in the two sides of the binary and their interrelations, following Kaniadakis advice on the need to integrate different viewpoints to explore the process of technological innovation (Kaniadakis 2006). The BoAP approach developed in the field of Science and Technology studies. Emerging as a research program in the mid2000s drawing from the Social Shaping of Technology (SST) and merging concerns shared by the Edinburgh School and Helsinki School. The BoAP continues the emphasis of the study of technology in the making and it makes explicit the longstanding tradition within the of STS studies of combining detailed ethnographic studies with historical data. 
Given the illegality of the phenomena, much of the details regarding the design and building of the smugglers' artifacts are not recorded. However, sources such as court records and Navy and military documents offer valuable sources on the details of the social practices and often on the technical choices faced by smugglers. Official records regarding navy patrol boats are surprisingly scarce. Ethnographic work in the Navy workshops provided a detailed description of the procuring of Navy boats. Official documents capture in the form of snapshots the entry of new artifacts, but state actors often let aside the context and details in which such entry took place and most routine modifications of existing boats and practices. To fully capture the diversity and variation of artifacts that take part in the WoD, it is necessary to trace and combine historical sources and the point of encounter and spaces in which decisions about smuggling/enforcement are taken.

Following BoTP advice I seek to capture users practices, interactions arenas, using interviews and ethnographic work to understand the process involved in the development of existing artifacts. Interviews also provided evidence regarding the 'evolution' of the technologies used in the WoD. Using triangulation of sources I account for the historical dimension of the phenomena, comparing data from different qualitative methods, observations, interviews and official and public documents. I used a thematic analysis, indexing recurrence of themes and sorting the data in 'organizational categories' or 'topics' (Maxwell and Chmiel 2014).

\section{The dispersed character of drug smugglers innovation}

Illicit drugs are transported in different quantities, using both existing infrastructures (such as ports, airports, roads) or using unpoliced areas as departure points, and building makeshift 
docks or airstrips. Reports on the seizure of cocaine declared the weight of the shipments, (from just a few grams up to several tons) for which smugglers resort to a vast array of camouflage methods. Some of them involve formal knowledge, (i.e., chemistry) and others of artisanal work; and quite often, a combination of both. Since the 1990s, as reported by enforcement agencies maritime transport methods (UNODC 2010) are the preferred strategy used by drug smugglers to transport bulk amounts of cocaine.

In transporting their cargo using maritime routes, drugs smugglers have used existing infrastructure and unpoliced spaces in both the Caribbean and Pacific Coast of Colombia. To transport drugs over sea, smugglers have used a combination of speed and camouflage by: (1) gaining tactical-logistical knowledge of the workings of port security and its vulnerabilities, using the inherent mobility of the shipping container as well as other forms of cargo shipping (Martin 2015); (2) using traditional small cargo boats or fishing boats to transport cocaine and deploying a logistic chain to provide fuel and to transship in the open sea; (3) using recreational boats, either as purchased or modified with compartments to transport illicit drugs; (4) using traditional boats, such as pangas, often with modifications to gain speed attaching outboard engines or purchasing off-the-shelf solutions, such as go-fast boats and; (5) designing and building the narcosubs.

Little is known about how narcosub designers organize themselves and how designs are decided on or modified. The design, building, and use of the narcosub is sometimes assumed to be the result of 'cartels' who hire 'expert knowledge', such as naval engineers who then recruit builders. Reports on the captures and trials of individuals involved in the building of narcosubmarines allow to establish the variety of arrangements for the production of a 
Preprint currently under consideration by ST\&HV: Please do not cite without the author's consent

narcosub. Two main arrangements are distinguishable. The leader of a criminal network may contact designers with or without experience in the building of such artifacts, and provide

the funding to build the narcosubs. Designers of the narcosubs might approach leaders of criminal networks and offer their services and designs. While financers often visit the building sites or send 'consultants' with expert knowledge. Builders are hired from the local area, and transported to the areas where narcosubs are being built, which are also the areas where they will depart from.

\section{The evolution of the narcosubs}

I turn now my attention to those custom-made vessels. Narcosubmarines, drug subs, narco semisubmersibles, Self-Propelled Semi-Submersibles, or simply narcosubs, are custommade maritime vessels mainly used by Colombian drug smugglers and developed with the purpose of transporting illicit drugs into the U.S. market. The term narcosub encompasses a diversity of artifacts that includes semisubmersible vessels and fully submersible vessels. They are characterized by the use of maritime diesel engines, a rudimentary cooling system, no facilities, and a valve that if captured by Law Enforcement Agencies or Military, which allows water to fill the artifact and sink the vessel. Narcosubs are not made to last, as smugglers, mostly discard such vessels after completing their one-trip journey. The narcosubs are more related to the makeshift version of submarines used by the Tamil guerrillas, than to traditional military submarines.

Smugglers have been using narcosubs from at least since 1993, but the most captures have been made since 2005, and in the Colombian Pacific coast. The Navy describes narcosubs as highly difficult to detect and track, because they produce no emissions once they depart, and 
their little wake makes them difficult to locate. Narcosubs have been adapted to navigate in the different conditions offered by the Caribbean Sea and the Pacific Ocean.

The mix and match approach used by narcosub builders have resulted in high variation of the narcosubs. The process of innovation in the design and building of such artifacts is constrained by the illegality of the activity, limiting the availability of materials and imposing difficulties for the transport of such materials to the building sites. Faced with conflicting constraints both from their internal organization and the interaction with the environment (Kauffman and Macready 1995) smugglers are left with alternative, locally optimal, negotiated solutions for the transport of illicit drugs. The pictures (Figure 1) demonstrates the variation and dispersion in the designs of the narcosubs, as a result of a range of sociotechnical conditions.

As evidenced by the captured from 1993 until 2016, both in the open sea or in the construction phase in the makeshift shipyards demonstrate a broad combination of materials, different designs, and building techniques indicating various approaches preferred by disconnected groups of drug smugglers to solve a common problem, namely, the transportation of bulk amounts of cocaine. Narcosub designers benefit from the pattern of dispersed peer innovation (Hyysalo and Usenyuk 2015), in which the design and construction of these vessels, not being bound by standardized procedures, profit from the possibilities of creating their designs with high degrees of flexibility when exploring the different aspects of the "techno-meme." Those involved in the process of antagonist innovation can mix locally-available knowledge of traditional boat building with off-the-shelf technologies. The propeller exemplifies the results of this variation in the procurement of the parts and materials for the building of narcosubs. 
While some low profile vessels and semisubmersibles use either propellers from available manufacturers, new or second hand, easily available in near shops, other users prefer custommade propellers. In several instances, the Navy and Police have found propellers labeled as handmade (hechizas in Spanish) ${ }^{1}$. Furthermore, custom-made propellers as identified by Navy technicians, can be the built in local workshops by local technicians applying traditional knowledge boat building techniques or formal naval engineer knowledge.

The design and building patterns of the narcosubs are the result of two different approaches: first, attempts to build a submarine or semi-submarine vessel; and, second, micro modifications to established artifacts with the aim of improving their speed or camouflage which, in the process, became a different artifact. The latter is the case of the low-profile vessels. A kind of narco submarine resulting from the placing of a roof covering the whole artifact (Figure 2). This variation was earlier perceived in the go-fast as to gain speed and to protect the cargo (Figure 3). The design and construction of narcosubs depend on what is available regarding both knowledge and materials, and local traditions of boats building play an essential role in choices concerning materials used in building the hull. In tropical areas where traditional boat building has used wood as the primary material for the construction of pangas and other small fishing boats, the majority of narcosubs are built around a wood hull covered in the glass fiber. The presence of formal knowledge considerably affects the design and building of narcosubs. Ex-naval officers with degrees in naval engineering designed the narcosub in Figure 4.

\footnotetext{
${ }^{1} \mathrm{~A}$ term to name artifacts as homemade in opposition to procured from manufacturers.
} 
The materials used to build the narcosubs cooling systems further demonstrate the dynamics of design and construction. Characteristically in the semisubmersible types of narcosubs, the "gooseneck" ventilation tubes remain visible above water, while exhaust pipes either remain visible in most of the seized artefacts or, in some other vessels, they are located below the waterline together with heat exchangers tubes. The quantity, shape, and materials of the ventilation pipes in the "gooseneck" shape that allows the intake of air for the engine room and the cabin, vary widely. Some users prefer off-the-shelf technology for the ventilation pipes, either bronze or PVC pipes, while in other models the goosenecks are custom made in glass fiber (Figure 5). Air extractors are used to help air exchange. In some instances, the exhaust pipes are coated with different fibers to reduce heat. Some models possess an intricate pipeline as in industrial double pipe heat exchangers running alongside the vessel to cool down the machine room as the ship moves (Figure 6), an innovation that also helps to reduce the heat signature emitted by the powerful diesel engines and makes the detection by infrared detectors more difficult.

Another feature of the narcosub that seems to be present in most of the variants of this artifact is the existence of a valve that allows water to flow inside the artifact and, in fact, sink the artifact and any evidence in case of being detected by LEAs or the Navy. Destroying one's artifact as the tactical move (Papadopoulos and Tsianos 2013), the crew abandon the vessel wearing life vests or by inflating a small life boat, they turn a smuggling operation into a shipwreck and the interdiction operation into a search and rescue operation by restoring to a long tradition of sailors' honor of helping other sailors in the sea. This practice extended to artifacts built both in the Pacific and Caribbean, and after the Anti-submersible law was 
passed these occurrences diminished, because the law now permits visual evidence to be sufficient to prosecute the crew of the artifact for trafficking offenses.

Sailors of the narcosubs build a relationship of trust with the builders through multiple trials before sailing. Trust in the faultless functioning of the artifact is a crucial aspect of their use, for the sailor's life depends on it. During my ethnographic work, informants emphasized the perils of sailing those artifacts in the open sea, which are often called 'water coffins.' Sailors often participate in the latter stages of the construction of the narcosubs, during a testing phase, providing their expertise to ensure the reliability of the main systems.

In theoretical terms, the overview of the patterns of innovation in the case of the narcosubs provides an entry point to reflect on the process of innovation in outlaw environments, an interstice in the language of BoAP. Narcosubs emerged as a user-driven solution to the problem of transporting big amounts of illicit drugs while evading state action, from an initial stage of experimenting and prototyping to the dynamics of dispersed peer innovation. The diversity of smugglers' artifacts cannot be explained as the results of a process of continuous innovation, but as a combination of different approaches to solve the same problem, as undertaken by diverse groups producing different bricolages (Büscher et al. 2001).

Innovations on the drug traffickers' side emerge in the context of competition with other smuggling groups and state agencies. Such as the description offered by Anderson (2015) of the competition between migrants and the border technologies, in which failure in controlling the flows generated a dynamic in which more controls are placed. What is interesting in the $\mathrm{WoD}$, is the importance of locality for the development of those controls. 


\section{Locality in the development of interdiction technologies and practices}

The involvement of the Colombian Navy in the WoD began in the late 1970's and early 1980's, when it carried out operations against marihuana smugglers in the Caribbean Sea. Those encounters involved old blue-water vessels and old frigates, against small and medium-sized fish and cargo boats. The full-on involvement of the Navy in the WoD only came with the boost of the Coast Guard Unit in 1994, a branch of the Colombian Navy directly attached to the Chief of Naval Operations. Operational success, in turn, began to be measured in terms to seizures of illicit drugs.

The development of technologies for the interdiction of the flows of illicit drugs can be placed within the trends of intensification of the efforts to control globalized flows since the early 1980s (Andreas 2003; Kaufmann 2016) along with the continuous militarization of the WoD. The patrol boat, a relatively small boat, use mostly to defense and custom duties, is in the WoD deployed by the Colombian Navy as an offensive tools against to contain the illicit flows.

The deployment of the military to counter criminal activities (Reitano, De Lugo, and Jesperson 2018) has led to descriptions of the binary interdiction/evasion as equal to inflexibility/flexibility to explain for the competitive advantage of smugglers. Traits of network arrangements, especially the flexibility attached to 'Network Flexibility' understood as the ease with which a network rearranges itself - replace nodes if they decline while maintaining the logic of the network (Urry 2005) is set to apply also to 'smugglers networks, 
explaining the difficulties for catching up of state agencies (Kenney 2007a). According to this view what is needed is more technology and flexibility if state agencies are to control such flows.

Narratives concerning interdiction and border control technologies stress in the low-tech/hitech distinction, and such categorizations is part of the identification strategies of security professionals; besides they serve as a marker of identity and pride (Bonelli and Ragazzi 2014). While the upper echelons of law enforcement agencies emphasize in the role of communication and detection technologies as a vital component in the success of the WoD, personnel in the field expresses the need to quickly adapt to local conditions and smugglers practices as a critical element, for which small improvements in the patrol boats are usually enough. The analysis of the different avenues for procurement, maintenance and improvement of the patrol boats by the Colombian Navy, exemplifies how those changes challenge the traditional interpretation of the binary interdiction/evasion concerning technological innovation and change. My argument here is that the process of innovation on the interdiction's side of the binary interdiction/evasion, of the vehicle responsible for encounters with drug traffickers in the open sea, is the result of processes of local improvement, adaptations and, modifications; as result what officers and Non-Commander Officers (NCOs) experience in the field is the primary resource orienting the technological choices. That is to say, said artifacts are embedded in a set of socio-material practices.

The boats used as interdiction vessels were obtained from several sources: (1) donations from the U.S. Government; (2) procurement from the local naval industry; (3) repurposing seized smugglers' boats; (4) development of boats between the Navy and Navy Shipyard; and (5) 
procurement from the international market. In turn, the patrol boats that participate in the process old boats are modified to increase speed and adapt to local conditions; smuggling repurposed to be used for interdiction operations; boats are designed and constructed, either as a local innovation activity or with the intervention of formal engineering knowledge (e.g. the beast and the Orca); received as donations or bought from the U.S. Government and or vendors (Figure 7).

Patrol boats are subjected to modifications, and they are "tamed" by the users, patrol boats are incorporated, often suspiciously, into an established set of practices and are later adapted or discarded according to what official and NCOs perceive the local conditions and threats to be. Different vessels used as patrol boats have a similar biography: an initial moment at which the boat is considered a suitable tool; a second moment of discomfort with the vessel due to modifications, damages, or perceptions of the enemies' vessels and strategies; finally, the vessel is discarded or repurposed to be replaced with a new and "more" suitable one.

\section{Local events as a source of innovation}

Events, successfully thwarting drug-smuggling operations, are central to officers and NCOs. For local commanders and the personnel under their command, these seizures are turned into "events," which are essential to boost their careers and prestige, and that of the institution. However, they also shape the technological and practical choices of the Navy in regard to the WoD. The development, improvements, and workarounds in the patrol boats, can be analyzed as result of solutions to localized views that are often in conflict with global solutions proposed by the central command. 
The Dolphin was the first proper patrol boat employed by the Colombian coast guard in interdiction operations, although not designed for the open sea. Constructed as a bay and riverine patrol boat, it is a $7.81 \mathrm{~m}$ long, $2.60 \mathrm{~m}$ wide fiberglass boat, propelled by two $200-\mathrm{hp}$ outboard engines, and no armor. It was employed in hot pursues in open sea. A Navy officer, a direct user of the Dolphin, illustrates this point: "The Dolphins were useful...really useful in inland waters...but to go out in the sea...so...to go to the open sea, they were not so good there...they weren't designed to do that...the engines were too small...not designed to be used in the open sea" (Interview). Local commanders and mechanics changed several features of the Dolphins to respond to different local issues. Encounters with smugglers, failed operations and interpretations of drug traffickers' capabilities set the stage for the developing of local micro innovations in the boats. The Dolphin was, in some areas, fitted with light armor and heavy machine guns. Lacking communication systems, when in charge of interdiction operations, Navy officers began to carry out, their own early GPS devices, and radio with them. Those devices were later fitted into the boats.

The boat underwent two more transformations to match the perceived capacity of drug smugglers, speed. The first transformation was refitting the overboard engines or placing new ones. Another critical intervention was enlarging the boat, a process of trial and error to make it more suitable to the waves of the Pacific Ocean. Those changes were performed by Navy mechanics in local workshops to some Dolphin boats participating in interdiction operations in the Pacific, extending their size by 0.6 to $1.2 \mathrm{mt}$ and testing the maneuverability of the boat after the modifications. A Colombian vendor eventually built a new version of the 
Dolphin $^{2}$. The accumulation of local experiences of interdiction operations demonstrated that smugglers had already overcome the capacities of refitted Dolphins. The description of a Navy captain exemplifies such experience: "The Dolphin became completely useless to control drug traffickers... because if a go-fast boat... reaching... the Dolphin was reaching more or less 30 knots... the go-fast could reach 50 knots per hour" (Interview).

By the late 1990's and early 2000's, two different local approaches and two that included centralized control were adopted to face the new capability of drug smugglers. Repurposing drug smugglers' boats and self-building artifacts were local efforts. Purchasing go-fast boats from local vendors and designing and building go-fast boats were efforts to centralize strategies to thwart drug smugglers' activities.

Smugglers' boats offered the advantage of having already been involved in interdiction operations; however, their characteristics were known by naval personnel. Using smugglers' repurposed boats also unified the field and often shifted the balance in favor of the coast guard personnel. Despite having similar potential speeds, smugglers' boats were necessarily slower due to their weight, illicit cargo, provisions, and gas. The use of repurposed boats reveals the dynamism of actions in the WoD. Those lobster boats are one of many instances in which the binary interdiction/evasion clearly shows its symbiotic characteristics. After

\footnotetext{
${ }^{2}$ The Company in charge of building the Colombian version of the Dolphin was Eduardo Londoño e Hijos Sucesores, S. A. Eduardoño, S.A., a company based in Medellin with offices in Bogota, Buenaventura, and Cartagena. This company built mostly small boats in polyester and PRFV, between 4 and $13 \mathrm{~m}$ long, to be used in transport, fisheries, and sports activities, until commissioned by the Navy to construct the Dolphin.
} 
seeing the performance of the boat, Coast Guard personnel developed a sense of personal security regarding its use when compared with others boats. Trust in the boats is a critical factor for the coast guard during interdiction operations. The experience of a Navy officer further illustrates locality as a critical element in the technological choices made by naval personnel:

We had these boats...the Dolphins...well... as we were facing drug trafficking, ...we were noticing that the Dolphins were useless...that the smugglers rode on Lobster boats...so every lobster boat we can lay our hands on...we put on the Coast Guard stripes... and we started to operate on them... and soon we started to achieve results (events) (Interview).

A different approach was applied in the Caribbean coast. The chief of naval operations in the area decided to design and build of a fast interceptor boat. The new boat was to be used in the Caribbean Sea, and officers with formal training in naval engineering working together with an external team were in charge of designing it. Besides, Navy mechanics in the premises of the naval base were tasked with building the artifact. The requirements of officers and NCOs were focused on speed; they assumed that a boat capable of a sustained speed of 45 knots per hour was a match for smugglers' boats. Lack of resources and attention of the central command resulted in the cancellation of the project soon after four boats were completed. These boats were nicknamed the beasts, due to their capacity. The interceptor was able to achieve a speed up to 60 knots in still waters and could easily turn around, an important feature to face evasive actions. The commander in charge of the solution was 
transferred, and it was decided that the procurement of boats was going adopt traditional means.

Procuring boats from local vendors was proposed as the centralized solution to face drug smugglers. Nevertheless, the boats acquired by the Navy were also used by some drug smugglers, who could purchase them off the shelf to carry drugs and discard them after the trip $^{3}$. The boats were designed and built by the same company in charge of the Colombian version of the Dolphin, and they featured a 31.5 hull, which was considered a suitable tool by the naval personnel. The hulls were also subjected to local modifications. Those modifications demonstrated to the coast guard personnel that a boat, when used with vendor characteristics, was usable but rarely adapted to interdiction operations, for which constant communication and more extended periods in the open sea were needed. The boats were fitted with new communication systems, antennas, and roofs, which unbalanced the center of gravity. Those changes implied risks when conducting hot pursues.

Another attempt to provide a centralized solution to the problem was designing and building, in the early 2000's, a new patrol boat deemed to become the main rapid interceptor patrol boat replacing all previous ones. The task was entrusted as a maiden project to Cotecmar, the recently established Navy shipyard at the time. Since the beginning, the project adopted a commanding engineering view. The resulting boat was called the Orca. The final design was a fiberglass $11.8-\mathrm{m}$ long, 2.6-m wide hull with three 200-hp engines, 500 nautical miles of

\footnotetext{
${ }^{3}$ It is worth pointing out that this was not the only vendor available to smugglers, but they have been a dominant brand in boat building and selling in Colombia.
} 
range, and a five-person crew; it could reach speeds of up to 40 knots when fully loaded or 60 knots on a smooth sea and carrying naval personnel only. It costed half the price of similar artifacts available in the market, and it turned out to be unfit for interdiction operations in open sea. Trials of the Orca were carried out by Coast Guard personnel with experience in high-speed pursuits in early 2003, and they provided hints of several problems with the vessel as well as the foreseeable problems of carrying out interdiction operations. The main problem with the vessel was its shape which, at high speed, increased the possibilities of sinking; besides, it could only achieve those speeds in calm sea conditions and without the wake of rival boats.

During the mid-2000's, a new U.S. government donation, the Midnight Express boat, was used by the Colombian coast guard unit. Together with this new boat, the interdiction operations were carried out with an assortment of new, old, and self-built boats, ships procured from local vendors or repurposed vessels. In theoretical terms, the evolution of the patrol boats demonstrates the complex relationship of users with technologies in antagonistic relations. The naval personnel exercise a high degree of autonomy in the customization of the boats in the field; conversely, centralized efforts offer off-the-shelf solutions or a commanding engineering vision, which rarely fit local needs.

The variety of boats used by the Navy can be described as the result of a balance between the expectations provided by generic technologies (which are expected to be applied with minor adjustments only) and configurational technologies (Fleck 1988, 1994), in which existing components are adopted, modified, and recombined to create new forms adapted to interdiction requirements. Before 2013, most vessels in both sides of the binary 
interdiction/evasion could be considered bricolages, combining the old and the new, and shaped by users' requirements for specific circumstances of use.

\section{Conclusions}

The cases presented in this article describe the way antagonist environments can create the conditions for technological innovation. Based on the analysis of documental data and ethnographic observation, I conclude that, in such conditions, rather than depending on central control or decision making, the local understanding of threats and solutions is essential. As such, the users on both sides of the binary continuously search for solutions and modify the technologies. These examples clearly demonstrate the role of users in antagonistic relationships. By bringing smuggling vehicles as well as those designed to stop them to the fore, we can deepen our understanding of the way actors in such situations innovate. These are the relationships I present under the concept of antagonist innovation.

The two sides of the binary demonstrate similar developments, both evolving with the introduction of new artifacts, but mainly due to continuous alterations to existing artifacts. The continuous alteration of existing artifacts may lead to the creation of a new class of technology; this is the case of the narcosub or the production of self-built artifacts by smugglers and the Colombian Navy. The production of those modifications and new artifacts can be traced to locally-available knowledge, which is sometimes complemented with formal education. Knowledge of local practices of boat building and participating in smugglers' artifact testing allows to build trust with the artifacts. Additionally, knowledge of the mechanics and their skills, as well as discussions over reparations and improvements, also 
develop trust between the naval personnel and the vessels they use during interdiction operations.

The main characteristics of this antagonist innovation can be summarized as follows:

- Importance of local views: Both sides of the binary interdiction/evasion build their technologies shaped by the local perceptions of the enemy, mainly using locally-available materials and knowledge.

- Flexibility: Both sides of the binary are capable of modifying and building new artifacts. Not only drug smugglers can quickly change and adapt technologies, naval personnel are also able to catch up with smugglers' machines by using local resources to introduce micro innovations into their machines.

- Trust: Interdiction operations are unusually violent affairs. Nevertheless, naval personnel and drug smugglers need to rely upon their machines for their survival. Drug smugglers using narcosubs or other makeshift vessels need to develop a sense of trust with their machines by knowing them and participating in their construction or tests.

- Symbiotic: The analysis of the vehicles used to smuggle drugs and stop them allows to provide a critical account of the binary interdiction/evasion. Such analysis does not reproduce a binary opposition; multiple connections dissolve the binary and entangle the two sides, thus furthering their symbiotic relationship. First, the locality and local perceptions of the threats shape the technologies on both sides. Second, the same set of resources are used to tinker with and build their artifacts. Third, a similar set of machines (namely, boats) has been employed for smuggling and interdicting. 
I have conceptualized the process of technological innovation in antagonist relationships as antagonist innovation, demonstrating that players on both sides of the binary modify their machines but also build their artifacts according to localized perceptions of enemies' capacity and machines.

\section{References}

Andersson, Ruben. 2015. "Hardwiring the Frontier? The Politics of Security Technology in Europe's 'Fight against Illegal Migration.'” Security Dialogue 47 (1): 22-39.

Andreas, Peter. 2003. "Redrawing the Line: Borders and Security in the Twenty-First Century." International Security 28 (2): 78-111.

Bagley, Bruce. 1991. "Mitos de La Militarización: Los Militares Estadunidenses y La Guerra Contra Las Drogas.” Foro Internacional 32 (1): 17-46.

Bonelli, Laurent, and Francesco Ragazzi. 2014. "Low-Tech Security: Files, Notes, and Memos as Technologies of Anticipation.” Security Dialogue 45 (5): 476-93.

Boville, Belén. 2004. The Cocaine War: In Context : Drugs and Politics. Algora Publishing.

Büscher, Monika, Satinder Gill, Preben Mogensen, and Dan Shapiro. 2001. "Landscapes of Practice: Bricolage as a Method for Situated Design.” Computer Supported Cooperative Work (CSCW) 10 (1): 1-28.

Chepesiuk, Ron. 1999. "International Drug Trafficking and the War on Drugs: A Historical Overview." In The War on Drugs: An International Encyclopedia, edited by Ron Chepesiuk, xix-xxxiv. Santa Barbara, California; Denver, Colorado; Oxford, England: ABC-CLIO.

Coopersmith, Jonathan. 1998. "Pornography, Technology, and Progress." ICON 4: 94-125.

- 2000. "Pornography, Videotape and the Internet." IEEE Technology and Society 
Magazine, no. Spring: 27-34.

—. 2006. "Does Your Mother Know What You Really Do? The Changing Nature and Image of Computer-Based Pornography." History and Technology 22 (1): 1-25.

Decker, Scott H, and Margaret Townsend Chapman. 2008. Drug Smugglers on Drug Smuggling Lessons from the Inside. Philadelphia: Temple University Press.

Escobar, Roberto, and David Fisher. 2009. The Accountant's Story Inside the Violent World of Medellin Cartel. New York: Hachette Book Group.

Fleck, James. 1988. “The Development of Information Integration: Beyond CIM?” In . Edinburgh PICT Working Paper. Edinburgh: University of Edinburgh.

—. 1994. "Learning by Trying: The Implementation of Configurational Technology." Research Policy 23 (6): 637-52.

Flowers, Stephen. 2008. "Harnessing the Hackers: The Emergence and Exploitation of Outlaw Innovation.” Research Policy 37 (2): 177-93.

Flowers, Stephen, and Flis Hendwood. 2010. "Introduction: Perspectives on User Innovation.” In Pespectives on User Innovation, edited by Stephen Flowers and Flis Hendwood, 1-8. Technology Managment. London: Imperial College Press.

Gambardella, Alfonso, Christina Raasch, and Eric von Hippel. 2016. "The User Innovation Paradigm: Impacts on Markets and Welfare.” Management Science 63 (5): 1450-68.

Gootenberg, Paul. 2008. Andean Cocaine: The Making of a Global Drug. Latin American Studies. Anthropology. Chapel Hill: University of North Carolina Press.

Hyysalo, Sampsa. 2009. "User Innovation and Everyday Practices: Micro-Innovation in Sports Industry Development.” R\&D Management 39 (3): 247-58.

Hyysalo, Sampsa, Neil Pollock, and Robin Williams. 2018. "Method Matters in the Social Study of Technology: Investigating the Biographies of Artifacts and Practices." Science \& 
Technology Studies XX, no. X: 1-24.

Hyysalo, Sampsa, and Svetlana Usenyuk. 2015. “The User Dominated Technology Era: Dynamics of Dispersed Peer-Innovation.” Research Policy 44 (3): 560-76.

Kaniadakis, A. 2006. "The Agora of Techno - Organisational Change." The University of Edinburgh.

Kauffman, Stuart, and William Macready. 1995. "Technological Evolution and Adaptive Organizations: Ideas from Biology May Find Applications in Economics.” Complexity 1 (2): $26-43$.

Kaufmann, Stefan. 2016. "Security Through Technology? Logic, Ambivalence and Paradoxes of Technologised Security.” European Journal for Security Research 1 (1): 77-95.

Kenney, Michael. 2007a. From Pablo to Osama Trafficking and Terrorist Networks, Goverment Bureaucracies, and Competitive Adaptation. University Park, Pennsilvania: The Pennsilvania State University Press.

—. 2007b. "The Rules of Drug Trafficking: Decision Making in Colombian Narcotics Enterprises.” In Handbook of Decision Making, edited by Göktug Morcöl, 361-71. Boca RatónLondonNew York: Taylor \& Francis.

—. 2007c. "The Architecture of Drug Trafficking: Network Forms of Organisation in the Colombian Cocaine Trade." Global Crime 8 (3): 233-59.

Martin, Craig. 2015. "Smuggling Mobilities: Parasitic Relations, and the Aporetic Openness of the Shipping Container.” In Cargomobilities, Moving Materials in a Global Age, edited by John Urry, Thomas Birtchnell, and Satya Savitzky, 65-86. New York; Oxon: Routledge. Maxigas. 2017. "Hackers against Technology: Critique and Recuperation in Technological Cycles." Social Studies of Science 47 (6): 841-60.

Maxwell, Joseph A, and Margaret Chmiel. 2014. "Notes Toward a Theory of Qualitative Data 
Preprint currently under consideration by ST\&HV: Please do not cite without the author's consent

Analysis.” In The SAGE Handbook of Qualitative Data Analysis, edited by Uwe Flick, 21-

35. Thousand Oaks, London, New Delhi: Sage Publications.

Mejia, Daniel. 2016. "Plan Colombia: An Analysis of Effectiveness and Costs.” Washington, D.C.

Papadopoulos, Dimitris, and Vassilis S. Tsianos. 2013. "After Citizenship: Autonomy of

Migration, Organisational Ontology and Mobile Commons.” Citizenship Studies 17 (2): 17896.

Reitano, Tuesday, Lucia Bird Ruiz-Benitez De Lugo, and Sasha Jesperson. 2018. Militarised Responses to Transnational Organised Crime: The War on Crime. Cham, Switzerland: Cham, Switzerland: Palgrave Macmillan.

Rochlin, J im. 2011. "Plan Colombia and the Revolution in Military Affairs: The Demise of the FARC." Review of International Studies 37 (02): 715-40.

Russell, Stewart, and Robin Williams. 2002. "Concepts, Spaces and Tools for Action? Exploring the Policy Potential of the Social Shaping Perspective.” In Shaping Technology, Guiding Policy Concepts, Spaces and Tools, edited by Knut H Sørensen and Robin Williams, 13354. Chelthenham, UK; Northampton, MA, USA: Edward Elgar.

Schulz, Celine, and Stefan Wagner. 2008. "Outlaw Community Innovations.” International Journal of Innovation Management 12 (3): 399-418.

Shah, Sonali K. 2006. "From Innovation to Firm Formation: Contributions by Sports Enthusiasts to the Windsurfing, Snowboarding \& Skateboarding Industries The Engineering of Sport 6." In , edited by Eckehard Fozzy Moritz and Steve Haake, 29-34. Springer New York.

Söderberg, Johan. 2017. “Comparing Two Cases of Outlaw Innovation: File Sharing and Legal Highs.” In Critical Studies of Innovation, edited by Benoît Godin and Dominique Vinck, 115-136. Cheltenham, UK.

Taylor, P A. 1999. Hackers: Crime in the Digital Sublime. London and New York: Routledge. 
UNODC. 2010. The Globalization of Crime. A Transnational Organized Crime Threat Assessment. Vienna: United Nations Office on Drugs and Crime.

Urry, J. 2007. Mobilities. Cambridge, [England] ; Malden, MA: Polity.

Urry, John. 2005. “The Complexities of the Global.” Theory, Culture \&amp; Society 22 (5): 23554.

Usenyuk, Svetlana; Whalen, Jack; Hyysalo, Sampsa. 2016. "Proximal Design: Users as Designers of Mobility in the Russian North.” Technology and Culture 57 (4): 866-908.

Voss, Georgina. 2007. "The Dynamics of Technological Change in a Socially Stigmatised Sector." In DRUID-DIME Academy Winter 2007 PhD Conference on Geography, Innovation and Industrial Dynamics. Aalborg, Denmark.

Zaitch, Damián. 2002. Trafficking Cocaine: Colombian Drug Entrepreneurs in the Netherlands. The Hague: Kluwer Academic Publishers. 